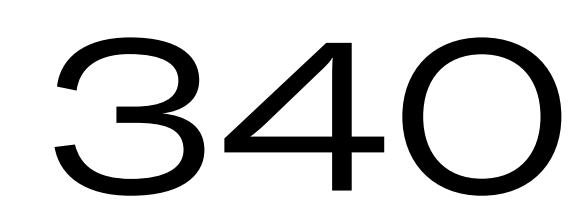

\title{
Última nota
}

\section{Antonio Candido}

Resenha inédita sobre Origens e fins, segundo

livro de Carpeaux, publicada no rodapé da

Folha da Manhã, em 1944. 
ÚLTIMA NOTA

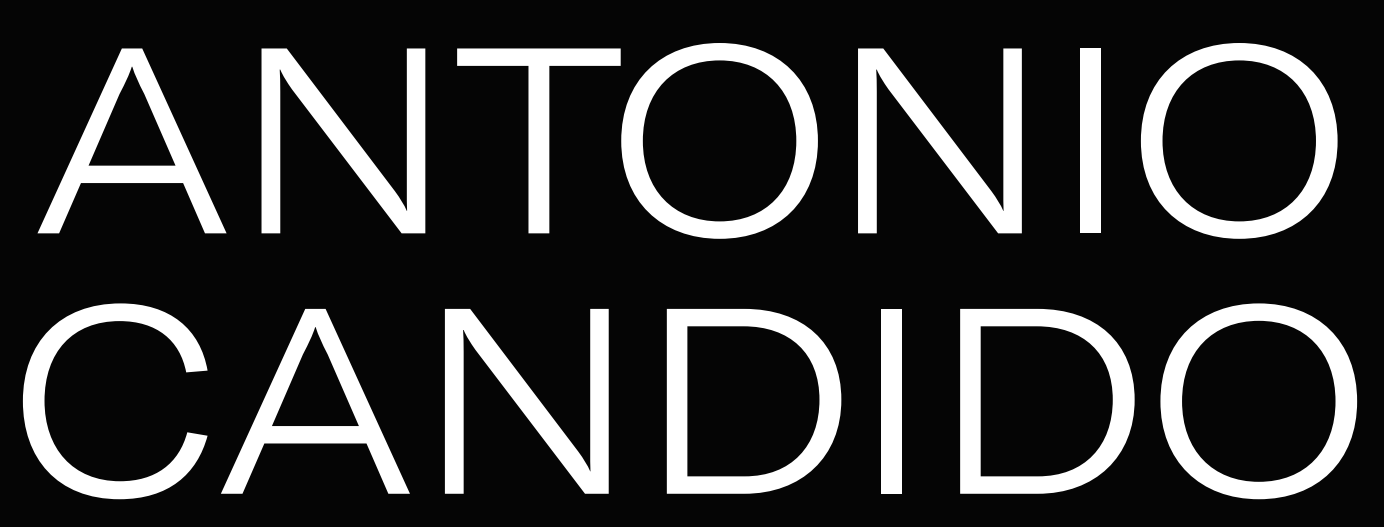


Finalizando as notas sobre poetas e poesia, quero chamar a atenção do leitor para um livro recente, onde encontrei meditações das mais bem orientadas sobre a matéria. Quero referir-me à Origens e fins, do sr. Otto Maria Carpeaux. Pode-se dizer que um terço dos artigos nele enfeixados (9 sobre 26) versam sobre problemas de poesia. E eu prefiro apresentarvos este aspecto do pensamento do autor, já por ser o mais característico da sua maneira - já por entrar na linha das nossas últimas cogitações minhas e, quero crer, vossas, leitor.

Fazendo um justo reparo ao sr. Álvaro Lins, o sr. Otto Maria Carpeaux afirma direção interpretativa da sua própria crítica em divergência com o critério judicativo daquele autor. Com efeito - e aqui me ponho ao lado do sr. Otto Maria Carpeaux - a crítica interpretativa é mais fecunda mormente se precisarmos optar entre ela e a judicativa - porque o critério ideal seria um movimento que, partindo da análise interpretativa, chegasse ao diagnóstico funcional, passando pelo julgamento de valor. É o defeito de grande parte dos ensaios do autor que nos ocupa, não só neste como no seu primeiro livro, é o que se poderia chamar o excesso de interpretação. Com efeito o sr. Otto Maria Carpeaux adota, para interpretar, o processo comparativo. Ora, a comparação é uma espécie de presente de gregos. Timeo comparatio et dona ferentes... Pode nos esclarecer largamente o caminho crítico, tornando-se deste modo um dos instrumentos mais fecundos de trabalho, como pode nos levar ao analogismo, fazendo sair do seu bojo, uma série de traidores que nos envolvem e nos levam a escamotear o problema, trocando o juízo crítico pela muleta da comparação, como diria Ronald de Carvalho, o pior dos críticos comparativos malgré lui que o Brasil já teve. Em mais de um ensaio, sobretudo do seu primeiro livro, o sr. Carpeaux parece cair nessa armadilha, reduzindo o seu trabalho, no final das contas, a um passeio ameno e instrutivo pelos vários jardins das literaturas europeias. Quando, porém, consegue se livrar do perigo, nos dá ensaios de primeira ordem, graças a extensão dos seus conhecimentos e das suas leituras. 
Não sou um leitor muito assíduo da nossa imprensa nem dos nossos articulistas, mas me parece que o sr. Otto Maria Carpeaux foi o primeiro, no Brasil, a comentar a poesia de acordo com as modernas tendências da crítica inglesa e americana dos nossos dias - isto é, a constatar, diante, da realidade da produção dos poetas, que a poesia moderna era, em larga parte, uma espécie de retomada da poesia conceituosa do barroco: gongorismo, marinismo, poesia metafísica, como chamou Johnson à dos poetas da primeira metade dos seiscentos inglês. É sabido que os poetas ingleses modernos, influenciados por Eliot, que por sua vez, se embebera em Donne, Marvel etc. a exemplo de Yeats em parte da sua obra e, sobretudo, de Gerard Manley Hopkins, o grande didata do verso inglês contemporâneo, empregam largamente os processos poéticos subordinados, mais ou menos, à lição cultista. Alguns críticos chegam a ver na poesia não cultista, como a romântica, por exemplo, uma quebra da verdadeira evolução da poesia inglesa. Outros sustentam que o romantismo não rompe, mas retoma a tradição cultista, limpando-a, rompendo com a artificialidade do wit e recobrando a espontaneidade da imagem em oposição à sua intelectualidade excessiva. Citemos, como exemplo do primeiro grupo, o americano Cleanth Brooks (v. o seu livro: Modern Poetry and the Tradition) e, do segundo, o inglês Herbert Read (v. os seus Collected Essays in Literary Criticism). Por outro lado, como aprendi com o sr. Carpeaux, operava-se na Espanha uma idêntica busca em relação à obra dos culteranos, sobretudo do seu pontífice, o paulificante e grande Don Luís de Góngora.

É assim que vemos um poeta moderno, como Cecil Day-Lewis, fazer poesia social empregando, ao lado e ao mesmo tempo que outros, os processos requintados e não raro obscuros do desenvolvimento antitético, da imagem-valor, do conceito, exatamente como se encontram nos "Holy Sonnets" do velho e longamente esquecido John Donne. O leitor ficará facilmente inteirado da questão lendo, em nossa língua, os admiráveis "Passos da Cruz" nas Poesias recém-publicadas de Fernando Pessoa, e comparando-os com os sonetos seiscentistas de Rodrigues Lobo ou os poemas de Dom Francisco Manoel. Verá, então, até que ponto o simbolismo e as sutilezas do poeta português moderno se entroncam nos seus velhos e sábios patrícios de trezentos e mais anos atrás.

O problema pode, grosseiramente, se resumir no seguinte. Há duas linhas de poesia: uma que faz da imagem um apoio ilustrativo do desenvolvimento do poema, devendo este ser sobretudo a expressão de 
uma realidade perceptível através de uma identificação sentimental; outra, que faz da imagem uma unidade expressiva autônoma, que se exprime a si mesma e que deve ser percebida por um movimento tanto intelectual quanto afetivo. A segunda, evidentemente, requer uma acuidade e uma atenção contínua. A necessidade de um certo treinamento anterior e de um esforço permanente a tornam mais difícil e, portanto, mais obscura. Esta questão é das mais debatidas da crítica anglo-americana dos nossos dias. Não há quem não meta nela a sua colher torta. A magnífica antologia Reading Poems, comentada por mim neste rodapé há uns dois meses, pode-se dizer que é construída em torno dela.

Ora, na literatura brasileira, onde não constitui um problema vital, até aqui ninguém a tem abordado publicamente. No entanto, a sua importância é tão decisiva para as questões gerais de poética, o seu esclarecimento tão fecundo para a famosa discussão da poesia moderna, que não há como agradecer o sr. Otto Maria Carpeaux por tê-la divulgado entre nós. Aliás, um dos seus méritos mais fecundos tem sido justamente trazer para o Brasil uma inteligência afeita aos problemas do velho mundo e estudado os nossos à sua luz, esclarecer mais de um ponto de vista de ordem geral.

O sr. Otto Maria Carpeaux é dos que acham que a verdadeira linha da poesia é a do conceito e da chamada pureza. O seu gosto coincide com o dominante na crítica inglesa moderna. Segue uma curva segundo a qual a poesia, depois do fecundo século XVI e do barroco, dá um pulo, passando alto sobre o classicismo malherbeano e drydeneano, o romantismo, o parnasianismo, para se encontrar novamente no simbolismo e nas correntes modernas. No entanto, a sua posição não é tão simples. Aprende muito bem o sentido da evolução poética moderna, e poucas vezes tenho lido páginas tão lúcidas e tão decisivas quanto àquelas em que fala da passagem da poesia privada para a poesia pública como tendência e condição de grandeza da poesia moderna. Da mesma maneira, o seu estudo entre as relações da poesia e da ideologia demonstra uma segurança de quem já ultrapassou as brigas relativas à função da poesia, colocando-se num plano mais essencial, que permite a visão esclarecida do problema. Creio que o sr. Carpeaux tem um certo preconceito crítico, podendo-se aplicar-lhe o que ele próprio escreve, citando Richards: "Sedimentos de teorias críticas que prescrevem à poesia um papel determinado e condenam um poema em que está desempenhado um outro papel à poesia”. O Parnaso e o Romantismo 
brasileiros são para ele movimentos de terceira ordem. E mesmo, penso eu, os outros parnasos e romantismos, - a não ser o aspecto nervaliano ou hoelderlineano deste. Não fará o sr. Carpeaux uma injustiça, oriunda do seu esforço de estar de acordo com a atitude recente em poesia? Mas, se esta deve tanto, no Brasil pelo menos, a homens como Casimiro de Abreu, Gonçalves Dias, Olavo Bilac, Raimundo Correia! Tenho a impressão de que o nosso autor se perde um pouco na poesia mais marcadamente nacional, como é a solução indígena do Parnaso, num Vicente de Carvalho, por exemplo, ou o romantismo eloquente de um Castro Alves. É patente esta relativa falta de sensibilidade - explicável aliás, plenamente, num estrangeiro há poucos anos entre nós, e que já faz muito em nos compreender tão bem quanto compreende - na sua desconfiança diante da obra do sr. Mário de Andrade.

É evidente que, para um europeu, e para os que têm a sensibilidade marcada sem remédio pela cultura europeia, o sr. Mário de Andrade é pouco acessível, justamente por ser o mais brasileiro dos grandes poetas modernos e por apresentar uma riqueza de facetas própria a desconcertar quem não consiga entender a sua evolução. Só vi, até agora, dois estrangeiros entendê-lo plenamente: Roger Bastide, que o coloca na primeira plana da nossa poesia, e Giuseppe Ungaretti, que o considerava um dos maiores poetas do Brasil.

Não é, porém, em relação ao que considero falhas justificáveis numa cultura de fresca data que reside o meu desacordo com o sr. Otto Maria Carpeaux. A sua crítica me parece pecar por um certo excesso de confiança. Há na maioria dos seus ensaios, um certo ar de infalibilidade que nem sempre agrada. Uma insuficiência que faz lembrar às vezes o pavonismo do sr. Afonso Arinos de Melo Franco. Quando fala, por exemplo da "resistência dos ignorantes e estúpidos suficientes que se revoltam contra a poesia moderna" (me parece que a função do crítico literário é, antes, procurar pacientemente esclarecer os que não entendem); ou quando escreve coisas assim cortantes: "O que o sr. Álvaro Lins fez pela poesia brasileira contemporânea constitui obra definitiva"; "o pobre Banville, definitivamente enterrado" etc. Não estou de acordo, sobretudo, com o uso imoderado que faz o sr. Carpeaux do vocábulo dialética. Isso porque a dialética, para ele, é um processo parcial, aplicável apenas a certo tipo de desenvolvimento, sobretudo mental. A sua concepção da evolução histórica e da função do espírito está longe do que se pode chamar dialética como se pode ver sobretudo nos ensaios de $A$ cinza do purgatório, sobre Vico, 
Weber, Burckhardt. Ora, dialética tem um sentido tão perigoso hoje em dia, que não vejo como aplicar o vocábulo fora de uma concepção também dialética da história e do espírito.

O sr. Otto Maria Carpeaux é um dos mais seguros dentre os que agitam ideias literárias no Brasil. A sua atividade tem se revestido de um cunho de utilidade para os mais moços, porque representa, não é difícil ver, um apaixonada luta pela supremacia do espírito e pela revalorização dos princípios segundo os quais vivemos. Veja-se o seu belo ensaio sobre Lorca. Para a literatura brasileira, tem o inestimável valor de representar um ponto de vista europeu dentro dela, permitindo, deste modo, visões novas, orientações diferentes daquelas que já nos calejaram. O nível da sua produção, a largueza dos seus conhecimentos e a sua compreensão certa da função da crítica, fazem dele uma aquisição de primeira ordem para a nossa vida intelectual.

Folha da Manhã

São Paulo, 28 de maio de 1944 
A otto Maria Cappeaux, do sen contante aimirader

Antrimo Candidop.

FORMAÇÃO DA LITERATURA BRASILEIRA (MOMENTOS DECISIVOS)

1. ${ }^{\circ}$ VOLUME

(1750-1836) 